\title{
Testing species hypotheses for Fridericia magna, an enchytraeid worm (Annelida: Clitellata) with great mitochondrial variation
}

\author{
Svante Martinsson * (D, Mårten Klinth (1) and Christer Erséus (D)
}

\begin{abstract}
Background: Deep mitochondrial divergences were observed in Scandinavian populations of the terrestrial to semi-aquatic annelid Fridericia magna (Clitellata: Enchytraeidae). This raised the need for testing whether the taxon is a single species or a complex of cryptic species.

Results: A total of 62 specimens from 38 localities were included in the study, 44 of which were used for species delimitation. First, the 44 specimens were divided into clusters using ABGD (Automatic Barcode Gap Discovery) on two datasets, consisting of sequences of the mitochondrial markers COI and 16S. For each dataset, the worms were divided into six not completely congruent clusters. When they were combined, a maximum of seven clusters, or species hypotheses, were obtained, and the seven clusters were used as input in downstream analyses. We tested these hypotheses by constructing haplowebs for two nuclear markers, H3 and ITS, and in both haplowebs the specimens appeared as a single species. Multi-locus species delimitation analyses performed with the Bayesian BPP program also mainly supported a single species. Furthermore, no apparent morphological differences were found between the clusters. Two of the clusters were partially separated from each other and the other clusters, but not strongly enough to consider them as separate species. All 62 specimens were used to visualise the Scandinavian distribution, of the species, and to compare with published COI data from other Fridericia species.
\end{abstract}

Conclusion: We show that the morphospecies Fridericia magna is a single species, harbouring several distinct mitochondrial clusters. There is partial genetic separation between some of them, which may be interpreted as incipient speciation. The study shows the importance of rigorous species delimitation using several independent markers when deep mitochondrial divergences might give the false impression of cryptic speciation.

Keywords: BPP, DNA-barcoding, Enchytraeidae, Haplowebs, Multispecies coalescence, Species delimitation

\section{Background}

Molecular studies of organismal DNA have proven many traditionally accepted species rank taxa to be complexes of morphologically similar, so called cryptic, species (see [1]). Examples are found in most animal groups e.g., [2],

\footnotetext{
* Correspondence: svante.martinsson@bioenv.gu.se

Systematics and Biodiversity, Department of Biological and Environmental Sciences, University of Gothenburg, Box 463, SE-405 30 Göteborg, Sweden
}

including segmented worms (Annelida) e.g., [3-5]. Mitochondrial markers, in particular, sometimes reveal distinct clusters of individuals within a genetically diverse but morphologically coherent assemblage of specimens, but testing such clusters as species hypotheses (putative cryptic species) in a standardised manner is not trivial. Methodological advances in species delimitation, e.g., approaches based on the multi-species coalescent (see

(c) The Author(s). 2020 Open Access This article is licensed under a Creative Commons Attribution 4.0 International License, which permits use, sharing, adaptation, distribution and reproduction in any medium or format, as long as you give appropriate credit to the original author(s) and the source, provide a link to the Creative Commons licence, and indicate if changes were made. The images or other third party material in this article are included in the article's Creative Commons licence, unless indicated otherwise in a credit line to the material. If material is not included in the article's Creative Commons licence and your intended use is not permitted by statutory regulation or exceeds the permitted use, you will need to obtain permission directly from the copyright holder. To view a copy of this licence, visit http://creativecommons.org/licenses/by/4.0/ The Creative Commons Public Domain Dedication waiver (http://creativecommons.org/publicdomain/zero/1.0/) applies to the data made available in this article, unless otherwise stated in a credit line to the data. 
$[6,7])$ have been successfully incorporated in several studies on species delimitation in clitellate annelids e.g., [8-12]. A precise determination of species boundaries is important, not just for our understanding of the diversity of species, but also for their conservation e.g., [13-15]. There are also several cases where cryptic species within a species complex have been found to differ in important aspects of their biology, such as their response to pollutants [16, 17], predation risk [18], host preferences [19, $20]$, and habitat preferences [15, 21, 22].

During large-scale surveys of Clitellata in Scandinavia involving DNA barcoding (Erséus et al., ongoing work), we found deep divergence in the mitochondrial marker Cytochrome c Oxidase subunit I (COI) in the terrestrial worm, Fridericia magna Friend, 1899 [23] (family Enchytraeidae), suggesting that this taxon is a species complex. Fridericia magna (Fig. 1) is one of the largest species in the species-rich genus Fridericia Michaelsen, 1889 [24], and indeed one of the larger enchytraeids (see [25]). It is up to $50 \mathrm{~mm}$ long, and can consist of more than 90 segments [26], and is easily distinguished from congenerics by the combination of its large size, reduced chaetal numbers and red blood [26]. Originally described from the Lake district in England [23], it has a West-European distribution, with many twentieth century records from Spain in the south to Scotland in the north (Fig. 2A) [26]; a form from Romania, described as a subspecies of F. magna by Botea [27] is probably a different species [26]. A first specimen from Sweden was incorporated in a phylogenetic study by Erséus et al. ([28] as supplementary material). The species is mainly found in moist mineral soils, rich in organic material, and near rivers and lakes [26].

The aim of this study was to test whether the morphospecies Fridericia magna is a complex of several species or not, under the unified species concept [29], which postulates that the more lines of evidence for the existence of a "separately evolving metapopulation lineage", the higher degree of corroboration in species delimitation. We sorted the specimens into potential species, based on genetic distances in the two mitochondrial markers COI and 16S rDNA, and tested these species hypotheses using two species criteria, the fields for recombination [30] using haplowebs [31], and the multispecies coalescent species concept [32] using BPP (Bayesian Phylogenetics and Phylogeography) [33, 34] on two nuclear markers Histone H3 (H3) and the Internal Transcribed Spacer region (ITS).

\section{Results}

Geographical distribution and habitats of the sampled material

A vast majority of our 38 Scandinavian sampling sites of F. magna are located in a coastal zone, extending to about $30 \mathrm{~km}$ from the sea, in south-western Sweden and then west- and northwards along the Norwegian coast to $63^{\circ} \mathrm{N}$ in Möre og Romsdal (Fig. 2B; Table S1). A single record was more inland, in the Swedish province of Dalsland near the large Lake Vänern. The habitats are of

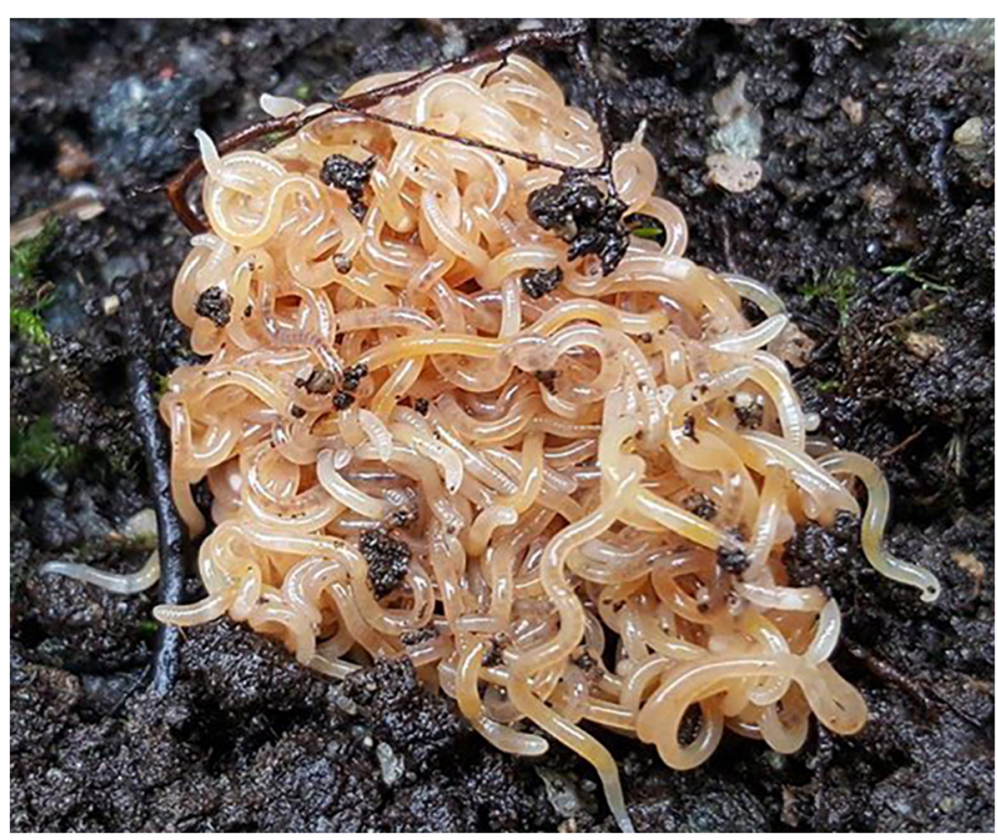

Fig. 1 An aggregate of Fridericia magna Friend, 1899 (Clitellata: Enchytraeidae); from the collection site of specimens CE31735-36; Photo by Kate Michelsen 


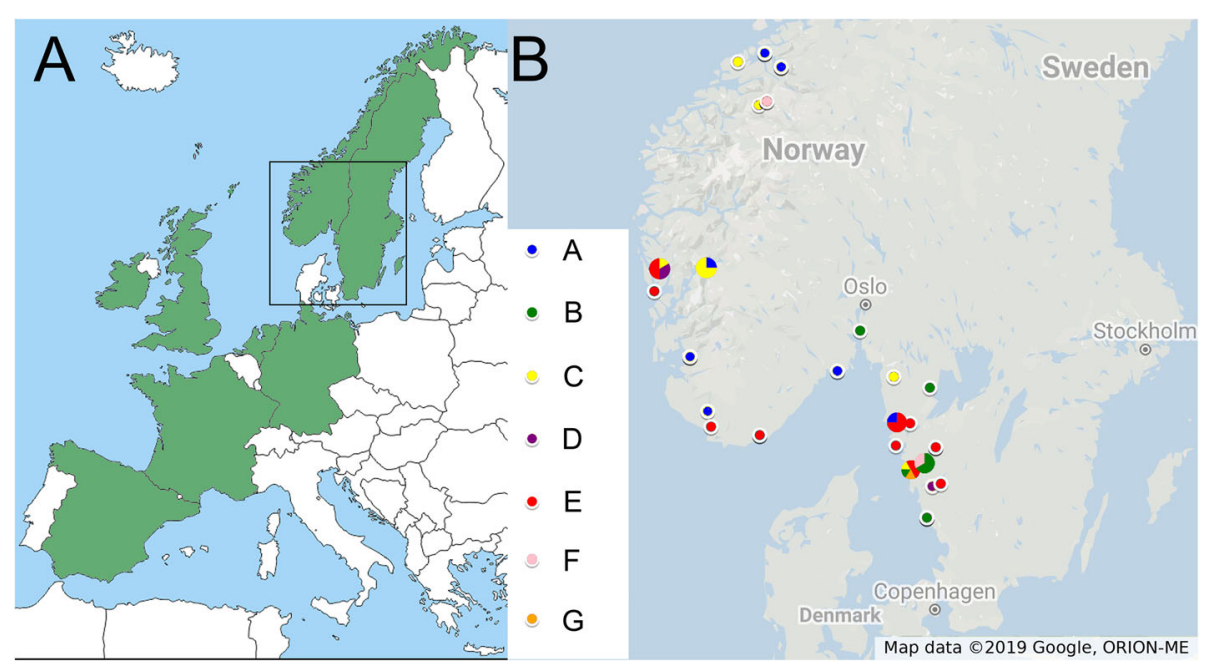

Fig. 2 A Distribution of Fridericia magna in Europe, based on Schmelz [26], the subspecies F. m. ssp. carpathica Botea, 1973 from Bulgaria is excluded as it most likely represents a separate species, the rectangle indicate the position of zoomed in map in B. B. Distribution of Fridericia magna specimens used in this study, coloured according to mitochondrial lineages. For clarity, some closely situated localities have been combined. The map in A is based a map from D-maps (available at https://d-maps.com/carte.php?num_car=2232), the map in B is created in Google Maps, both maps were further edited in Adobe Photoshop. An interactive version of the map in B can be found at https://www.google.com/maps/d/edit?mid=1c4qeFc-BtsOtzf-QbuMS4P80pVo2cZ58\&usp=sharing

varying kinds, often soil with high organic contents, but in about half of the cases, the substrates were wet or fully submersed in water. All collection sites are located in regions of Sweden and Norway with high annual precipitation (> $900 \mathrm{~mm}$ per year) $[35,36]$.

\section{Specimens, DNA extraction and assembly}

For all 62 specimens COI was obtained, $16 \mathrm{~S}$ and H3 were successfully sequenced for 44 specimens, ITS was successfully sequenced for 42 specimens. The two COI alignments consist of 44 and 62 sequences respectively, the $16 \mathrm{~S}$ alignment consists of 44 sequences, the COI alignments are $658 \mathrm{bp}$ long, and the $16 \mathrm{~S}$ alignment 483 bp. The ITS alignment is $950 \mathrm{bp}$ long with 74 sequences, the $\mathrm{H} 3$ alignment $328 \mathrm{bp}$ with 58 sequences; the higher numbers are due to the phasing of heterozygous sequences.

\section{Mitochondrial clustering and distance analysis}

Uncorrected pairwise distances (p-distances) in the COI dataset vary between 0.0 and $8.8 \%$ (Fig. S1), and in the $16 \mathrm{~S}$ dataset between 0.0 and $3.6 \%$. The ABGD analyses divided both datasets into six clusters, but the clustering is not exactly the same in the two markers: one cluster found by the COI data is divided into two clusters by $16 \mathrm{~S}$, and vice versa, giving a maximum of seven possible clusters (named A-G; see Figs. 3 and 4), which were further tested in subsequent analyses. The maximum intra-cluster pdistances in COI vary between 0.0 and $1.1 \%$ (Table S2), and in $16 \mathrm{~S}$ between 0.0 and $0.4 \%$ (Table S3), and the minimum inter-cluster $\mathrm{p}$-distances in $\mathrm{COI}$ vary between 1.5 and $8.8 \%$ (Table S2), and in $16 \mathrm{~S}$ between 0.0 and $3.4 \%$ (Table S3); the variation is visualised in the haplotype networks (Fig. 3A-B). At four collecting sites, two clusters were represented in sympatry (A+ $\mathrm{E}, \mathrm{B}+\mathrm{E}, \mathrm{C}+\mathrm{G}, \mathrm{C}+\mathrm{D}$, respectively; Table S1), and up to four clusters are found close to each other (at adjacent sites in Gothenburg; see Fig. 2B).

In the dataset with GenBank sequences of other Fridericia spp., the distances vary from 0.0 to $23.0 \%$ with a gap between 7.3 and $11.3 \%$ (Fig. S1). As the identification of many sequences on GenBank are doubtful, i.e., some sequences identified to the same species are widely separated, while some other sequences identified to different species are close together, we use this gap as an approximation of the separation of intra- and interspecies distances. The distances between many of the clusters of F. magna in COI are higher than the maximum intra-species distances in the GenBank dataset. However, in the COI gene tree with our F. magna specimens combined with data from GenBank (Fig. S2), most species (except $F$. magna) are represented by a single specimen or a few very similar sequences. This bias is likely to underestimate the intra-specific variation of the species represented in the GenBank data.

\section{Morphology}

In total 31 specimens were studied, 25 of which were sexually mature. All six studied clusters (no specimen of cluster $\mathrm{F}$ was available) agreed with the description of $F$. magna in Schmelz, Collado [37]; body size being 


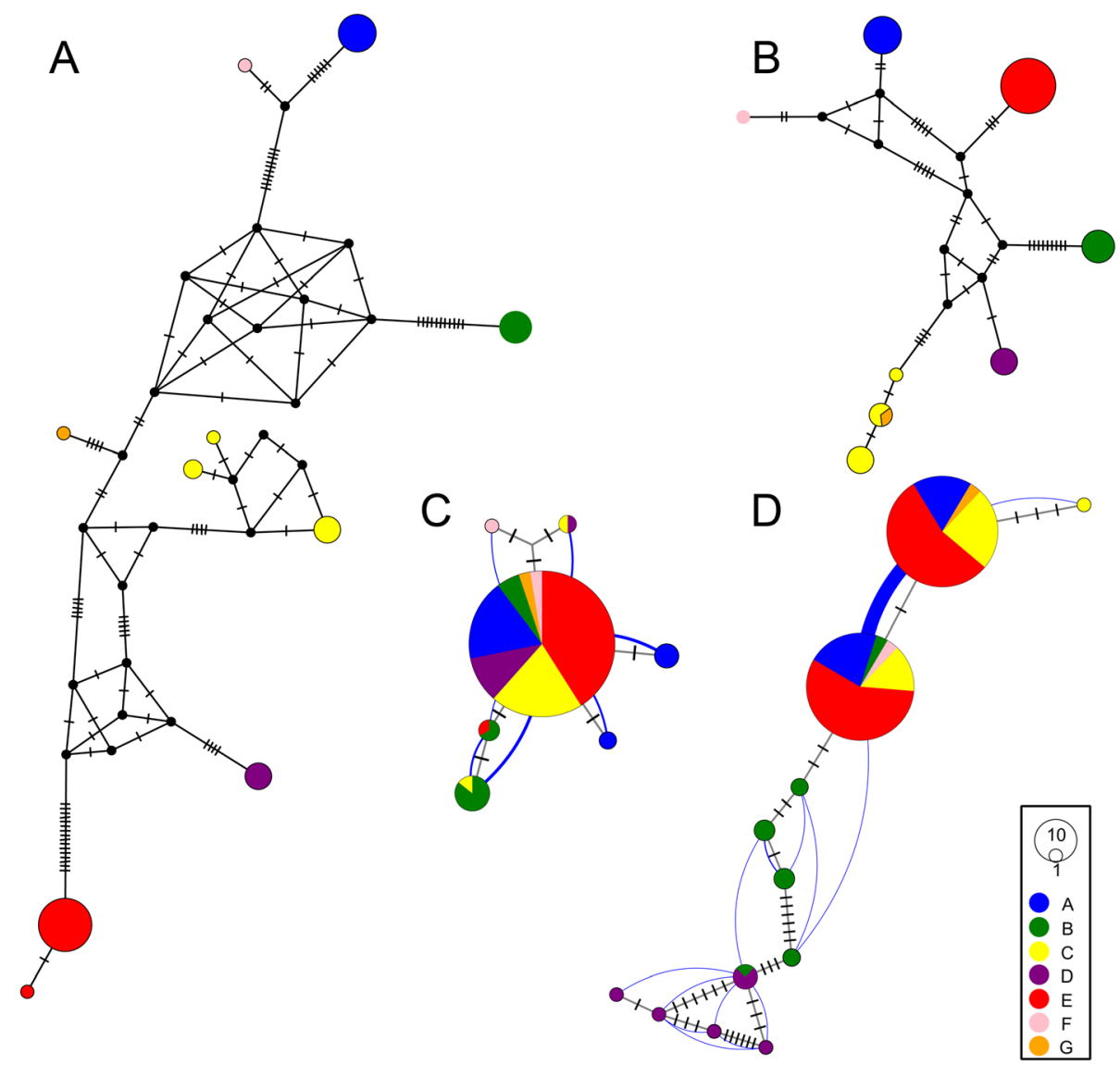

Fig. 3 Medium joining haplotype networks for A: COI B: 165 C: H3 and D: ITS. The size of the circles is relative to the number of individuals sharing that haplotype, the colours correspond to the mitochondrial clusters, A-G, used as input in the species delimitation analysis, and the hatch marks correspond to the number of substitutions between haplotypes. The H3 and ITS networks are haplowebs, with the blue lines connecting haplotypes found in the same individual, and the line thickness correlating with the number of individuals having both haplotypes

unusually large for Fridericia, and each spermatheca with two diverticula on the ampulla and two glands on the ectal duct, close to the ectal pore. However, we observed some slight differences in the chaetal pattern compared to the description in Schmelz, Collado [37]: in our material, the lateral chaetae were as commonly 1 as 2 (not mostly 2) per bundle, and the ventral chaetae were occasionally 1 , but usually $2-4$ per bundle anterior to the clitellum (not 3, or occasionally 4,1 or 0 per bundle). Although the chaetal pattern was variable throughout our sample of specimens, we could not find any consistent differences between the clusters.

\section{Haplowebs}

The haplowebs of the H3 and ITS datasets (Fig. 3C-D) both found only one species, as all haplotypes together form a single field for recombination. However, in the ITS haploweb (Fig. 3D) there is a tendency for cluster B and $\mathrm{D}$ to be separate, with only limited sharing of haplotypes between them and between $B$ and the other clusters.

\section{Multi-locus species delimitation}

Two of the three BPP analyses (A and B) found $F$. magna to be a single species, as none of the clusters were supported as separate species (Table 1). However in analysis $\mathrm{C}$, clusters $\mathrm{B}$ and $\mathrm{D}$ were well supported as separate with a mean PP of $>0.95$, in this analysis we used a population size prior assuming smaller genetic differences between random individuals from the population, than in the other two analyses. Based on the distances observed in the dataset, this prior is likely too small and therefore influences the analysis to accept more of the input species; the support for all input species is higher in analysis $\mathrm{C}$ than in A and B.

\section{Discussion}

The results are summarised in Fig. 4. As neither the haplowebs, nor the majority of BPP analyses, or morphology support splitting Fridericia magna into several species, we conclude that it is a single species.

Despite the distinct mitochondrial clusters found within $F$. magna, the consensus of the species 


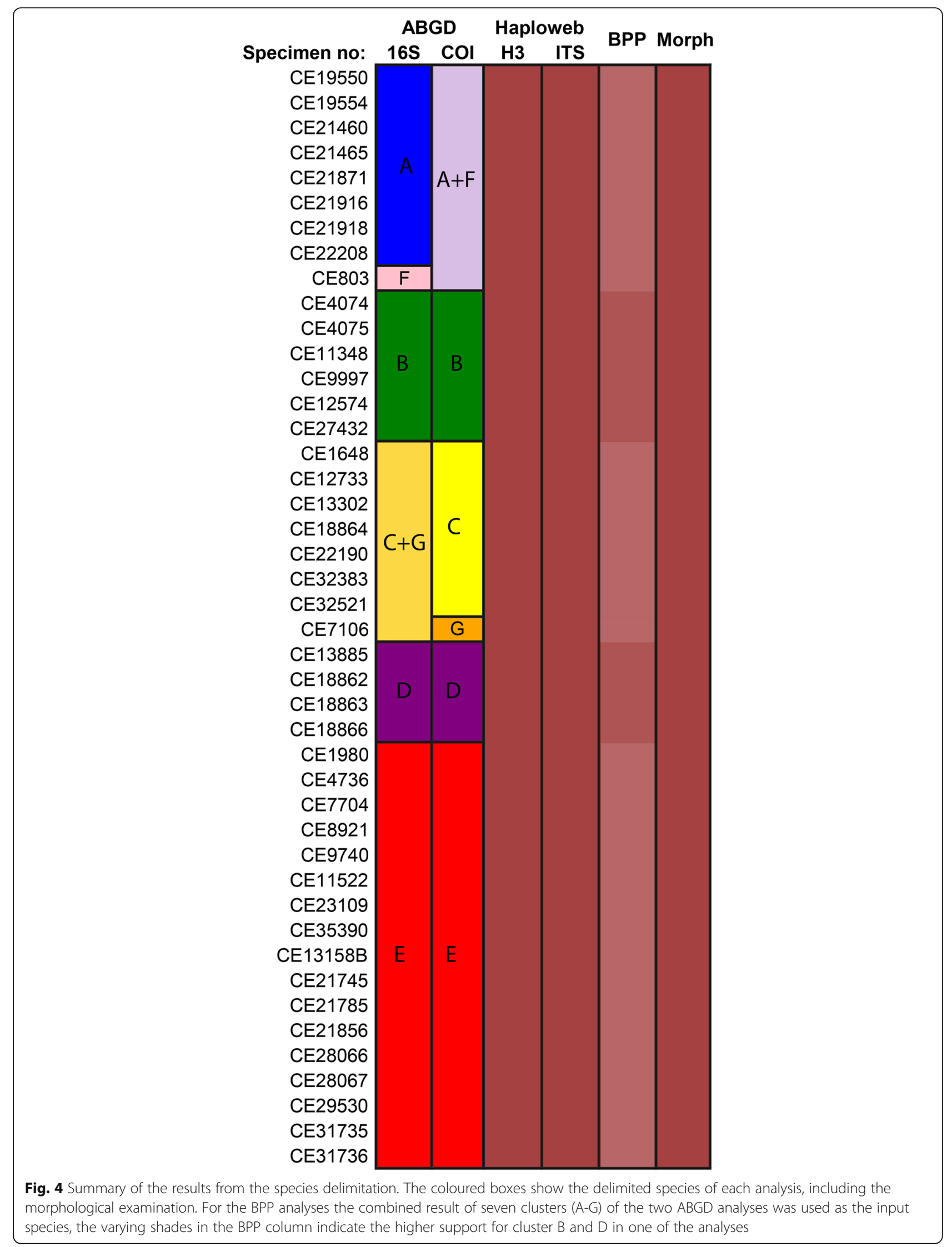


Table 1 List of species delimitations from the BPP analyses (AC) and their mean posterior probabilities (PP). PP $>0.90$ are marked in bold

\begin{tabular}{|c|c|c|c|}
\hline \multirow{2}{*}{$\begin{array}{l}\text { Species } \\
\text { delimitations }\end{array}$} & \multicolumn{3}{|c|}{ BPP analyses } \\
\hline & $\bar{A}$ & B & C \\
\hline A & 0.492 & 0.576 & 0.815 \\
\hline B & 0.727 & 0.744 & 0.972 \\
\hline C & 0.537 & 0.570 & 0.772 \\
\hline D & 0.701 & 0.720 & 0.955 \\
\hline$E$ & 0.438 & 0.512 & 0.738 \\
\hline$F$ & 0.596 & 0.625 & 0.829 \\
\hline G & 0.323 & 0.376 & 0.529 \\
\hline ABCDEFG & 0.251 & 0.231 & 0.000 \\
\hline CG & 0.096 & 0.079 & 0.127 \\
\hline EG & 0.093 & 0.104 & 0.149 \\
\hline AEG & 0.071 & 0.037 & 0.022 \\
\hline $\mathrm{AE}$ & 0.071 & 0.037 & 0.039 \\
\hline AG & 0.061 & 0.074 & 0.092 \\
\hline DF & 0.031 & 0.037 & 0.037 \\
\hline CEG & 0.021 & 0.032 & 0.017 \\
\hline CFG & 0.019 & 0.009 & 0.017 \\
\hline CF & 0.017 & 0.028 & 0.032 \\
\hline FG & 0.017 & 0.016 & 0.019 \\
\hline BF & 0.016 & 0.020 & 0.026 \\
\hline CE & 0.016 & 0.012 & 0.012 \\
\hline AEFG & 0.011 & 0.003 & 0.002 \\
\hline AF & 0.010 & 0.008 & 0.010 \\
\hline
\end{tabular}

delimitation methods support that all analysed specimens belong to a single species. Nevertheless, there is no completely randomized mixing of the clusters between the populations sampled. For ITS, clusters B and $\mathrm{D}$ were partly separated from the others, and from each other. This separation also got support by the BPP analysis $\mathrm{C}$. This could be incipient speciation, which with time would result in three separate species. It is also possible that we observed despeciation [38], where the three groups had earlier been separated as separately evolving populations, i.e., species sensu de Queiroz [29], but have later started to interbreed to such a degree that the boundaries between them are dissolving, and they no longer can be considered separate species. However, we cannot rule out the possibility that the pattern of incomplete mixing observed is simply due to the limited amount of specimens included in this study, and that the pattern would disappear when more specimens are included.

Fridericia magna is one of several species of Clitellata where deep mt-divergence has been reported e.g., [10, 39-42], and large mitochondrial genetic distances seems to be common within clitellate species. However, there are also cases of species being delimited with small genetic distances between them [43-45]. In species with low dispersal rates there are more subdivisions compared to related species with higher dispersal rates [46]. Unfortunately, dispersal rates are poorly known for enchytraeids, and to our knowledge there are no estimates of such under field conditions. However, an estimate based on laboratory experiments, for Cognettia sphagnetorum s.lat. is less than $1 \mathrm{~m}$ per year [47]. In lumbricid earthworms the rate of active dispersal has been estimated to between 1.5 and $14 \mathrm{~m}$ per year depending on species and habitat [48]. Based on these estimates, it seems reasonable to assume that the dispersal rate for $F$. magna is a few meters per year. Such a low rate may be one of the factors in the evolutionary history of $F$. magna for the mitochondrial divergence observed, but it does not explain the apparent lack of geographic structure in our sample. Fridericia magna seems to be rather easily washed into streams and transported downstream, which could increase the mixing of the mitochondrial lineages.

One common explanation for observed mitochondrial divergence in clitellates is that it evolved during the Pleistocene glaciations when different populations were separated in different refugia. However, this has not been formally tested. Fridericia magna has a W European distribution, and it seems reasonable to assume that it survived the Pleistocene glaciations in refugia in SW Europe. Considering the recent history of colonization of the current soil fauna in Scandinavia since the end of the Weichselian glaciation about 12,500 years ago [49], it is most likely that the great mitochondrial variation in our material was largely established in the more southern parts of Western Europe.

In our analysis of the pairwise genetic distances of the Fridericia spp. from GenBank there is a clear gap between 7.3 and $11.3 \%$. However, there are problems with the taxonomy of many of the sequences; in some clusters several species names are mixed, and another problem with this analysis is that for most species there is only a single sequence, or a few similar sequences available. These factors contribute to exaggeration of the global barcoding gap, and until a more complete dataset is available, with both more species and more sequences per species, it is hard to draw strong conclusions about the genetic variation within and between species of Fridericia.

The use of a single mitochondrial barcode, such as COI, is problematic, especially if a threshold distance is used as the main delimitation criteria, which was often the case in early DNA-barcoding literature e.g., [50, 51], and which is still in practice in the Barcode Index Number (BIN) System used by the Barcoding of Life Data System (BOLD) [52]. Instead it now seems that each 
case is unique, and a proper species delimitation analysis, including more data, is needed to establish the species boundaries. We urge taxonomists to test all species hypotheses using an integrative approach, involving also nuclear data, as well as organismal-level evidence, such as morphology, physiology, behaviour, life history traits, if possible.

\section{Conclusions}

We find no evidence that Fridericia magna specimens collected in SW Scandinavia, despite their great genetic variation, belong to a complex of cryptic species. The study underpins the problem with using only a single mitochondrial marker (a DNA barcode) together with a global threshold value in species delimitation (see [53]), instead each case should been seen as unique.

\section{Methods}

\section{Specimens, DNA extraction and assembly}

In total, 62 specimens of the morphospecies Fridericia magna, collected in Norway and Sweden (Fig. 2) between 2004 and 2016 (see Table 2, and Table S1 for details) are included in the study. For 19 of them only COI was sequenced, and these are not included in the species delimitation analyses. It can be noted that, at some of the sampling sites, numerous specimens had evidently been washed out from their natural habitats by heavy rain, and were found in aggregations (Fig. 1) in small temporary water bodies (puddles or flooding streams). One specimen (CE 23109) was found in stomach contents of a juvenile Atlantic Salmon (Salmo salar) caught in Bodeleån River, Uddevalla, Bohuslän, Sweden.

DNA was extracted from the posterior ends of ethanol-preserved worms, while the anterior parts of the same worms were either mounted in Canada balsam, or stored in $80 \%$ ethanol, to serve as physical vouchers. DNA was extracted using either Qiagen DNeasy Blood \& Tissue Kit or Epicentre QuickExtract DNA Extraction Solution 1.0, following the manufacturer's instructions. Four markers, the mitochondrial Cytochrome c oxidase subunit I (COI) gene, the mitochondrial ribosomal $16 \mathrm{~S}$ gene, the complete nuclear ribosomal Internal Transcribed Spacer (ITS) region, and the nuclear gene Histone $\mathrm{H} 3(\mathrm{H} 3)$, were amplified using primers and PCR programmes listed in Table S4. Sequencing was carried out by Macrogen Inc. (Seoul, Korea) or Eurofins MWG Operon (Ebersberg, Germany), 9 specimens were handled by the Canadian Centre for DNA Barcoding (CCDB) (Guelph, Canada), with data stored at the Barcode of Life Datasystems (BOLD), these are part of the 19 worms with COI data only (see above). As specified in Table 2 and Table S1, two sequences from Erséus et al. [28], and one from [54] were downloaded from GenBank. Moreover, for two specimens (CE18864,
CE18866), attempts at sequencing ITS were unsuccessful. Sequences were assembled in Geneious Pro v. 7.1 (Biomatters Ltd.; http://www.geneious.com) and aligned separately for each gene using MAFFT v7.017 [55], as implemented in Geneious Pro v. 7.1, using the autoalgorithm and default settings. For COI two datasets were created, one with the 44 species for which all markers were attempted to be sequenced, and one with all 62 COI sequences. A separate dataset consisting of all 129 Fridericia COI sequences available on GenBank (accessed 2 Jun 2020) was also assembled.

In the H3 and ITS datasets, several individuals showed clear signs of heterozygosity, i.e., distinct double peaks at certain positions in the sequencing chromatograms. Due to this, we separated H3 and ITS alleles using the PHASE algorithm $[56,57]$ as implemented in DNAsp v. 5.10 [58]. The phasing was run for 200 iterations after 100 initial burn-in iterations, with a thinning interval of 1 using default settings. For homozygous specimens only one of the two identical alleles was kept. Furthermore, two individuals had length variation in ITS, for these specimens phase determination was performed by direct sequencing [59] with the help of Champuru v1.0 [60], available online at http://www.mnhn.fr/jfflot/champuru/. The phased datasets were used in all subsequent analyses.

All new sequences produced in this study are deposited in GenBank, and the vouchers are deposited in either the Swedish Museum of Natural History (SMNH), Stockholm, Sweden, or the University Museum of Bergen (ZMBN), Bergen, Norway (accession numbers in Table S1).

\section{Mitochondrial clustering and distance analysis}

The F. magna specimens were clustered into groups using the two mitochondrial markers. Uncorrected genetic p-distances were calculated for the mitochondrial COI and 16S datasets in MEGA X [61], using pairwise deletion for missing data. The distances were then analysed with the online version of ABGD (Automatic Barcode Gap Discovery [62]; available at http://wwwabi.snv. jussieu.fr/public/abgd/abgdweb.html), with default settings, to divide the specimens into potential species. The latter were then subsequently tested using the nuclear markers (see below). The variation in COI and $16 \mathrm{~S}$ was visualized by haplotype networks created in PopART v1 [63] using medium joining [64]; sites with missing data or gaps were masked and not included in the networks. Uncorrected genetic p-distances were also calculated for the dataset of COI sequences from GenBank, and these were compared with the distance of the $F$. magna COI dataset and summarised in a histogram. A gene tree of all COI sequences, both from GenBank and the sequences of $F$. magna, combined was estimated with ML 
Table 2 Specimens, with GenBank accession numbers; accession numbers in bold face are newly generated; more details in Supplementary Table S1. Morphologically examined specimens are indicated by an asterix $\left(^{*}\right)$

\begin{tabular}{|c|c|c|c|c|c|c|c|c|}
\hline \multirow{2}{*}{$\begin{array}{l}\text { Specimen } \\
\text { no. }\end{array}$} & \multirow[t]{2}{*}{ Cluster } & \multirow[t]{2}{*}{ Country } & \multicolumn{6}{|c|}{ GenBank Accession no. } \\
\hline & & & $\mathrm{COI}$ & $16 S$ & ITS & & $\mathrm{H} 3$ & \\
\hline CE18491 & A & Norway & MT609948 & - & - & - & - & - \\
\hline CE18492 & A & Norway & MT609951 & - & - & - & - & - \\
\hline CE18493 & $A$ & Norway & MT609946 & - & - & - & - & - \\
\hline CE19550* & A & Norway & MT580300 & MT602462 & MT603764 & - & MT601975 & - \\
\hline CE19551 & $A$ & Norway & MT609947 & - & - & - & - & - \\
\hline CE19554* & A & Norway & MT580301 & MT602464 & MT603765 & - & MT601976 & - \\
\hline CE21460 & A & Norway & MT580303 & MT602467 & MT603768 & - & MT601978 & MT601979 \\
\hline CE21465 & A & Norway & MT580304 & MT602466 & MT603769 & - & MT601980 & MT601981 \\
\hline CE21871* & A & Norway & MT580308 & MT602468 & MT603774 & MT603775 & MT602002 & MT602003 \\
\hline CE21916* & A & Norway & MT580309 & MT602463 & MT603776 & - & MT601985 & MT601986 \\
\hline CE21918* & A & Norway & MT580310 & MT602469 & MT603777 & MT603778 & MT602004 & - \\
\hline CE21921 & A & Norway & MT580340 & - & - & - & - & - \\
\hline CE22208* & A & Norway & MT580312 & MT602465 & MT603781 & MT603782 & MT601987 & MT601988 \\
\hline CE4738 & A & Sweden & MT580332 & - & - & - & - & - \\
\hline CE12574* & B & Norway & MT580290 & MT602473 & MT603751 & MT603752 & MT601963 & - \\
\hline CE11348* & $B$ & Sweden & MT580288 & MT602470 & MT603747 & MT603748 & MT601960 & MT601961 \\
\hline CE27432* & B & Sweden & MT580314 & MT602475 & MT603785 & MT603786 & MT602008 & MT602009 \\
\hline CE4074* & $\mathrm{B}$ & Sweden & MT580323 & MT602471 & MT603799 & MT603800 & MT601991 & - \\
\hline CE4075* & B & Sweden & MT580324 & MT602474 & MT603801 & MT603802 & MT601992 & MT601993 \\
\hline CE4076 & B & Sweden & MT580331 & - & - & - & - & - \\
\hline CE9996 & B & Sweden & MT580334 & - & - & - & - & - \\
\hline CE9997* & B & Sweden & MT580329 & MT602472 & MT603813 & MT603814 & MT602000 & MT602001 \\
\hline CE12733* & C & Norway & MT580291 & MT602497 & MT603739 & MT603740 & MT601964 & - \\
\hline CE12734 & C & Norway & MT609954 & - & - & - & - & - \\
\hline CE13302* & $C$ & Norway & MT580293 & MT602498 & MT603755 & - & MT601966 & - \\
\hline CE18864* & C & Norway & MT580298 & MT602504 & - & - & MT601971 & MT601972 \\
\hline CE22190* & C & Norway & MT580311 & MT602499 & MT603779 & MT603780 & MT602005 & MT602006 \\
\hline CE32383* & C & Norway & MT580320 & MT602500 & MT603795 & MT603796 & MT602014 & - \\
\hline CE32521* & C & Norway & MT580321 & MT602502 & MT603745 & MT603746 & MT601990 & - \\
\hline CE1648 & C & Sweden & MT580295 & MT602501 & MT603757 & - & MT601968 & - \\
\hline CE18862* & D & Norway & MT580296 & MT602477 & MT603760 & MT603759 & MT601969 & - \\
\hline CE18863* & D & Norway & MT580297 & MT602478 & MT603762 & MT603763 & MT601970 & - \\
\hline CE18865 & $D$ & Norway & MT580335 & - & - & - & - & - \\
\hline CE18866* & D & Norway & MT580299 & MT602479 & - & - & MT601973 & MT601974 \\
\hline CE13885* & D & Sweden & MT580294 & MT602476 & MT603756 & - & MT601967 & - \\
\hline CE13158B* & E & Norway & MT580292 & MT602493 & MT603753 & MT603754 & MT601965 & - \\
\hline CE18454 & $E$ & Norway & MT609953 & - & - & - & - & - \\
\hline CE21745 & E & Norway & MT580305 & MT602481 & MT603770 & MT603771 & MT601982 & - \\
\hline CE21785 & $E$ & Norway & MT580306 & MT602487 & MT603772 & MT603773 & MT601983 & - \\
\hline CE21786 & E & Norway & MT580339 & - & - & - & - & - \\
\hline CE21856 & $\mathrm{E}$ & Norway & MT580307 & MT602482 & MT603741 & MT603742 & MT601984 & - \\
\hline CE28066 & $\mathrm{E}$ & Norway & MT580315 & MT602490 & MT603787 & MT603788 & MT602010 & - \\
\hline
\end{tabular}


Table 2 Specimens, with GenBank accession numbers; accession numbers in bold face are newly generated; more details in Supplementary Table S1. Morphologically examined specimens are indicated by an asterix $\left(^{*}\right)$ (Continued)

\begin{tabular}{|c|c|c|c|c|c|c|c|c|}
\hline \multirow{2}{*}{$\begin{array}{l}\text { Specimen } \\
\text { no. }\end{array}$} & \multirow[t]{2}{*}{ Cluster } & \multirow[t]{2}{*}{ Country } & \multicolumn{6}{|c|}{ GenBank Accession no. } \\
\hline & & & $\mathrm{COI}$ & $16 \mathrm{~S}$ & ITS & & $\mathrm{H} 3$ & \\
\hline CE28067 & $E$ & Norway & MT580316 & MT602488 & MT603789 & MT603790 & MT602011 & - \\
\hline CE29530 & $E$ & Norway & MT580317 & MT602494 & MT603791 & MT603792 & MT602012 & - \\
\hline CE31735* & E & Norway & MT580318 & MT602483 & MT603743 & MT603744 & MT601989 & - \\
\hline CE31736 & E & Norway & MT580319 & MT602495 & MT603793 & MT603794 & MT602013 & - \\
\hline CE11522* & E & Sweden & MT580289 & MT602485 & MT603749 & MT603750 & MT601962 & - \\
\hline CE1980* & E & Sweden & MT580302 & MT602480 & MT603766 & MT603767 & MT601977 & - \\
\hline CE1981 & $E$ & Sweden & MT580338 & - & - & - & - & - \\
\hline CE23109* & E & Sweden & MT580313 & MT602489 & MT603783 & MT603784 & MT602007 & - \\
\hline CE35390 & E & Sweden & MT580322 & MT602491 & MT603797 & MT603798 & MT602015 & MT602016 \\
\hline CE4736* & E & Sweden & MT580325 & MT602486 & MT603803 & MT603804 & MT601994 & - \\
\hline CE4737 & E & Sweden & MT580336 & - & - & - & - & - \\
\hline CE4739 & E & Sweden & MT580337 & - & - & - & - & - \\
\hline CE7704* & E & Sweden & MT580326 & MT602484 & MT603806 & MT603807 & MT601996 & - \\
\hline CE7715 & E & Sweden & MT580333 & - & - & - & - & - \\
\hline CE8921* & E & Sweden & MT580327 & MT602495 & MT603809 & MT603810 & MT601998 & - \\
\hline CE9740 & E & Sweden & MT580328 & MT602492 & MT603811 & MT603812 & MT601999 & - \\
\hline CE18487 & $\mathrm{F}$ & Norway & MT609949 & - & - & - & - & - \\
\hline CE18488 & $\mathrm{F}$ & Norway & MT609952 & - & - & - & - & - \\
\hline CE803 & $\mathrm{F}$ & Sweden & GU901804 ${ }^{1}$ & GU902066 ${ }^{1}$ & MT603808 & - & MN248702 ${ }^{2}$ & MT601997 \\
\hline CE7106* & G & Sweden & MT580330 & MT602503 & MT603805 & - & MT601995 & - \\
\hline
\end{tabular}

${ }^{1}$ From Erséus et al. [28]; ${ }^{2}$ From Schmelz et al. [54]

using phyML 3.0 [65]; Smart Model Selection [66] with Bayesian Information criterion was used for automatic model selection; and Subtree Pruning and Regrafting were used for tree improvement. Branch support was calculated with the SH-like (Shimodaira-Hasegawa test-like) approximative likelihood ratio test (aLRT) [67]. The tree was rooted using midpoint rooting and drawn in FigTree 1.4.2 [68] and further edited in Adobe Illustrator.

\section{Morphology}

Immature and sexually mature specimens from six of the seven potential species were examined morphologically, excluding cluster $\mathrm{F}$ for which we had no voucher (Tables 2, S1; both specifying which specimens that were mounted and examined). The characters examined were body size, chaetal formula and spermathecal morphology, other internal characters were difficult to observe in the whole-mounted material, due to the size of the worms. The morphology was compared to the description in Schmelz, Collado [37].

\section{Haplowebs}

To find the fields for recombination, i.e., groups of specimens that share a set of haplotypes connected by heterozygous individuals [30], haplowebs [31] were constructed for the nuclear ITS and H3 datasets with HaplowebMaker [69], available online at https://eeg-ebe. github.io/HaplowebMaker/, constructing median joining networks [64], and treating indels as a 5th character state. The haplotypes were coloured according to the mitochondrial clusters. Haplowebs visualise the fields for recombination by connecting haplotypes that are found within the same individual.

\section{Multi-locus species delimitation}

To test the potential species, under the multispecies coalescent species concept [32], multi-locus species delimitation was performed using BPP v.3.3 [34, 70], for the two nuclear markers H3 and ITS. As the COI and $16 \mathrm{~S}$ datasets were used for the initial sorting of specimens into groups, and therefore match the groups found by design, they were not included in the analyses. Joint Bayesian species delimitations and species tree estimations [33, 70, 71] were conducted; thereafter, three analyses $(\mathrm{A}-\mathrm{C})$ with different population size (estimated by $\theta$ ) and divergence time ( $\mathrm{\tau} 0$ ) priors were performed, using the same settings and priors as in Martinsson, Erséus [43] (A: $\theta$ 2, 400, т0 2, 200; B: $\theta$ 2, 1000, т0 2, 200;C: $\theta$ 2, 
2000, т0 2, 200); all are diffuse priors with $\alpha=2$, the difference between the analyses is in the population size prior $\theta$, which reflect the genetic distance between two sequences sampled at random from the population [34]. In analysis $A$ we used a large prior $(2 / 400=0.005)$, in $C$ a small prior, and with an intermediate prior in analysis B. The analyses were each run for 200,000 generations, discarding the first 4000 as burn-in, and all analyses were performed three times to confirm consistency between runs. We considered species delimited with a PP (posterior probability) $>0.90$ in all analyses to be well supported.

\section{Supplementary information}

Supplementary information accompanies this paper at https://doi.org/10. 1186/s12862-020-01678-5.

Additional file 1 Fig. S1. Histogram of uncorrected pairwise genetic distances given in percent for $\mathrm{COI}$ sequences of Fridericia spp. sequences from GenBank and F. magna from this study.

Additional file $\mathbf{2}$ Fig. S2. COI gene tree of our Fridericia magna specimens and $\mathrm{COI}$ sequences of Fridericia spp. from GenBank. The tree is estimated with Maximum Likelihood in PhyML. Scale show expected number of changes per site.

Additional file 3: Table S1. Specimens included in the study, with individual specimen numbers, collection data, museum voucher numbers, and GenBank accession numbers, accession numbers in bold are newly generated in this study. *Morphologically examined specimens mounted on slides. Table S2. Uncorrected pairwise genetic distances ( $p$ dist) in $\mathrm{CO}$ for the clusters of Fridericia magna, the intraclustal distances are given as the largest $\mathrm{p}$-dist and the intercluster distances as the smallest $\mathrm{p}$-dist. Table S3, Uncorrected pairwise genetic distances ( $\mathrm{p}$-dist) in $16 \mathrm{~S}$ for the clusters of Fridericia magna, the intraclustal distances are given as the largest p-dist and the intercluster distances as the smallest p-dist. Table S4. Primers and programs used for amplification and sequencing of fragments of the mitochondrial 165 and $\mathrm{COI}$ and nuclear ITS and $\mathrm{H} 3$ markers.

\section{Abbreviations}

16S: $16 S$ ribosomal DNA; ABGD: Automatic Barcode Gap Discovery; aLRT: approximative likelihood ratio test; BIN: Barcode Index Number; BOLD: Barcoding of Life Data System; BPP: Bayesian Phylogenetics and Phylogeography; CCDB: Canadian Centre for DNA Barcoding;

COl: Cytochrome c Oxidase subunit I; DNA: Deoxyribonucleic acid; E: East; H3 : Histone H3; ITS: Internal Transcribed Spacer; ML: Maximum Likelihood; N: North; no.: number; p-distances: pairwise distances; SH-like : ShimodairaHasegawa test-like; SMNH: Swedish Museum of Natural History; SW: Southwesten; W: West; ZMBN: University Museum of Bergen

\section{Acknowledgements}

The authors would like to thank, in particular, Emilia Rota, for helping us with the original morphological identification of Fridericia magna in Scandinavia; and Ainara Achurra, Mikael Andersson, Anna Ansebo, Alexander Bär, Thomas Dahlgren, Seana Davidson, Daniel Gustafsson, Per Hjelmstedt, Sam James, Tina Kutti, Emelie Lindqvist, Maria Lindström, Kate Michelsen, Joacim Näslund, Urban Olsson, Rasty Rafiq, Emilia Rota, and Endre Willassen, for providing specimens, or field and lab assistance; Kate Michelsen also for photographing live worms (Fig. 1).

\section{Authors' contributions}

All authors conceived and planned the project. CE did the majority of the field work, and was responsible for handling and storing specimens and the data regarding them. MK assisted in the field work, performed most of the lab work, as well as the morphological investigation of specimens. SM carried out the molecular analyses, and wrote the first draft. All authors were involved in the discussion and interpretation of the results. All authors edited and contributed to the manuscript, and read and approved the final version before submission.

\section{Funding}

Swedish Research Council for Environment, Agricultural Sciences and Spatial Planning (FORMAS); Swedish Research Council (VR), Swedish Species Information Centre (ArtDatabanken); the Norwegian Biodiversity Information Centre (Artsdatabanken); the Adlerbert Research Foundation; and the Royal Society of Arts and Sciences in Gothenburg (KWS); all to CE. The funding bodies played no role in any aspect of the study itself, including its design, the sampling procedures employed, the analyses and interpretation of the data and the writing of the manuscript. Open access funding provided by University of Gothenburg.

\section{Availability of data and materials}

The specimens included in this work are deposited in the Swedish Museum of Natural History (SMNH), Stockholm, Sweden, and the University Museum of Bergen (ZMBN), Bergen, Norway; accession numbers in Table S1. The DNA sequence data generated for this article are available on GenBank; see Table 2 for accession numbers. The DNA sequence alignments used in the analyses, as well as files associated with the BPP analyses, have been deposited on GitHub (https://github.com/Svante-Martinsson/Fridericia_ magna), and an interactive version of the distribution map in Fig. $2 \mathrm{~B}$ is available on https://www.google.com/maps/d/edit?mid=1c4qeFc-BtsOtzfQbuMS4P80pVo2cZ58\&usp=sharing

\section{Ethics approval and consent to participate}

Permits were not needed, and thus not obtained, for the collected specimens included in this study.

\section{Consent for publication}

Not applicable.

\section{Competing interests}

The authors declare that they have no competing interests.

Received: 4 November 2019 Accepted: 20 August 2020

Published online: 14 September 2020

\section{References}

1. Bickford D, Lohman DJ, Sodhi NS, Ng PK, Meier R, Winker K, Ingram KK, Das I. Cryptic species as a window on diversity and conservation. Trends Ecol Evol. 2007;22(3):148-55 https://doi.org/10.1016/j.tree.2006.11.004.

2. Pfenninger M, Schwenk K. Cryptic animal species are homogeneously distributed among taxa and biogeographical regions. BMC Evol Biol. 2007;7: 121 https://doi.org/10.1186/1471-2148-7-121.

3. Erséus C, Gustafsson D. Cryptic speciation in clitellate model organisms. In: Shain DH, editor. Annelids in modern biology. Hoboken, New Jersey: John Wiley \& Sons, Inc.; 2009. p. 31-46. https://doi.org/10.1002/9780470455203. ch3.

4. Nygren A. Cryptic polychaete diversity: a review. Zool Scr. 2014;43(2):172-83 https://doi.org/10.1111/zsc.12044

5. Liu Y, Fend SV, Martinsson S, Erséus C. Extensive cryptic diversity in the cosmopolitan sludge worm Limnodrilus hoffmeisteri (Clitellata, Naididae). Org Divers Evol. 2017;17(2):477-95 https://doi.org/10.1007/s13127-016-0317-z.

6. Fujita MK, Leache AD, Burbrink FT, McGuire JA, Moritz C. Coalescent-based species delimitation in an integrative taxonomy. Trends Ecol Evol. 2012; 27(9):480-8 https://doi.org/10.1016/j.tree.2012.04.012.

7. Rannala B. The art and science of species delimitation. Curr Zool. 2015:61(5): 846-53.

8. Klinth MJ, Martinsson S, Erséus C. Phylogeny and species delimitation of north European Lumbricillus (Clitellata, Enchytraeidae). Zool Scr. 2017;46(1): 96-110 https://doi.org/10.1111/zsc.12187.

9. Taheri S, James S, Roy V, Decaens T, Williams BW, Anderson F, Rougerie R, Chang $\mathrm{CH}$, Brown G, Cunha L, Stanton DWG, Da Silva E, Chen JH, Lemmon AR, Moriarty Lemmon E, Bartz M, Baretta D, Barois I, Lapied E, Coulis M, Dupont L. Complex taxonomy of the 'brush tail' peregrine earthworm Pontoscolex corethrurus. Mol Phylogenet Evol. 2018;124:60-70 https://doi. org/10.1016/j.ympev.2018.02.021 
10. Martinsson S, Erséus C. Hybridisation and species delimitation of Scandinavian Eisenia spp. (Clitellata: Lumbricidae). Eur J Soil Biol. 2018;88:417 https://doi.org/10.1016/j.ejsobi.2018.06.003.

11. Martinsson S, Rhodén C, Erséus C. Barcoding gap, but no support for cryptic speciation in the earthworm Aporrectodea longa (Clitellata: Lumbricidae) Mitochondrial DNA. 2017;28(2):147-55 https://doi.org/10.3109/19401736. 2015.1115487.

12. Erséus C, Klinth MJ, Rota E, De Wit P, Gustafsson DR, Martinsson S. The popular model annelid Enchytraeus albidus is only one species in a complex of seashore white worms (Clitellata, Enchytraeidae). Org Divers Evol. 2019; 19(2):105-33 https://doi.org/10.1007/s13127-019-00402-6.

13. Vogel Ely C, Bordignon SAL, Trevisan R, Boldrini II. Implications of poor taxonomy in conservation. J Nat Conserv. 2017;36:10-3 https://doi.org/10. 1016/j.jnc.2017.01.003.

14. Scherz MD, Glaw F, Hutter CR, Bletz MC, Rakotoarison A, Kohler J, Vences M. Species complexes and the importance of data deficient classification in red list assessments: the case of Hylobatrachus frogs. PLoS One. 2019;14(8): e0219437 https://doi.org/10.1371/journal.pone.0219437.

15. Davidson-Watts I, Walls S, Jones G. Differential habitat selection by Pipistrellus pipistrellus and Pipistrellus pygmaeus identifies distinct conservation needs for cryptic species of echolocating bats. Biol Conserv. 2006;133(1):118-27 https://doi.org/10.1016/j.biocon.2006.05.027.

16. Feckler A, Thielsch A, Schwenk K, Schulz R, Bundschuh M. Differences in the sensitivity among cryptic lineages of the Gammarus fossarum complex. Sci Total Environ. 2012;439:158-64 https://doi.org/10.1016/j.scitotenv.2012.09. 003.

17. Sturmbauer C, Opadiya GB, Niederstätter H, Riedmann A, Dallinger R. Mitochondrial DNA reveals cryptic oligochaete species differing in cadmium resistance. Mol Biol Evol. 1999;16(7):967-74.

18. Cothran RD, Henderson KA, Schmidenberg D, Relyea RA. Phenotypically similar but ecologically distinct: differences in competitive ability and predation risk among amphipods. Oikos. 2013;122(10):1429-40 https://doi. org/10.1111/j.1600-0706.2013.00294.x.

19. Hambäck PA, Weingartner E, Ericson L, Fors L, Cassel-Lundhagen A Stenberg JA, Bergsten J. Bayesian species delimitation reveals generalist and specialist parasitic wasps on Galerucella beetles (Chrysomelidae): sorting by herbivore or plant host. BMC Evol Biol. 2013;13(1):92 https://doi.org/10.1186/ 1471-2148-13-92.

20. Zhang C, Zhang DX, Zhu T, Yang Z. Evaluation of a bayesian coalescent method of species delimitation. Syst Biol. 2011;60(6):747-61 https://doi.org/ 10.1093/sysbio/syr071.

21. Lowe CN, Butt KR. Life-cycle traits of the dimorphic earthworm species Allolobophora chlorotica (Savigny, 1826) under controlled laboratory conditions. Biol Fertil Soils. 2006;43(4):495-9 https://doi.org/10.1007/s00374-006-0154-X

22. Eisenring $M$, Altermatt $F$, Westram AM, Jokela J, Peters DPC. Habitat requirements and ecological niche of two cryptic amphipod species at landscape and local scales. Ecosphere. 2016;7(5) https://doi.org/10.1002/ ecs2.1319.

23. Friend H. New British annelids. The zoologist (series 4). 1899:3:262-5.

24. Michaelsen W. Synopsis de Enchytraeiden. Abhandlungen aus dem Gebiete der Naturwissenschaften herausgegeben vom Naturwissenschaftlichen Verein in Hamburg. 1889;11(1-61).

25. Rota E. Oversized enchytraeids (Annelida, Clitellata): a comparative study, with a revised description of (Michaelsen). Org Divers Evol. 2001;1(3):225-38 https://doi.org/10.1078/1439-6092-00019.

26. Schmelz RM (2003) Taxonomy of Fridericia (Oligochaeta, Enchytraeidae). Revision of species with morphological and biochemical methods. Abhandlungen des Naturwissenschaftlichen Vereins in Hamburg (Neue Folge) $38: 415+437$ figs

27. Botea F. Enchtréidés (Oligochaeta) du domaine soutrerrain de Roumanie, Note 2. Travaux de I'Institut de Spéologie Émile Racovitza. 1973;12:87-111.

28. Erséus C, Rota E, Matamoros L, De Wit P. Molecular phylogeny of Enchytraeidae (Annelida, Clitellata). Mol Phylogenet Evol. 2010;57(2):849-58 https://doi.org/10.1016/j.ympev.2010.07.005.

29. de Queiroz K. Species concepts and species delimitation. Syst Biol. 2007; 56(6):879-86 https://doi.org/10.1080/10635150701701083

30. Doyle JJ. The irrelevance of allele tree topologies for species delimitation, and a non-topological alternative. Syst Bot. 1995;20(4):574-88 https://doi. org/10.2307/2419811.

31. Flot JF, Couloux A, Tillier S. Haplowebs as a graphical tool for delimiting species: a revival of Doyle's "field for recombination" approach and its application to the coral genus Pocillopora in Clipperton. BMC Evol Biol. 2010;10:372 https://doi.org/10.1186/1471-2148-10-372.

32. Aydin Z, Marcussen T, Ertekin AS, Oxelman B. Marginal likelihood estimate comparisons to obtain optimal species delimitations in Silene sect. Cryptoneurae (Caryophyllaceae). PLoS One. 2014;9(9):e106990 https://doi. org/10.1371/journal.pone.0106990.

33. Yang Z, Rannala B. Bayesian species delimitation using multilocus sequence data. PNAS. 2010;107(20):9264-9 https://doi.org/10.1073/pnas.0913022107.

34. Yang Z. The BPP program for species tree estimation and species delimitation. Curr Zool. 2015;61(5):854-65.

35. SMHI (2009) Normal uppskattad årsnederbörd, medelvärde 1961-1990. https://www.smhi.se/data/meteorologi/nederbord/normal-uppskattadarsnederbord-medelvarde-1961-1990-1.6934

36. Klimaservicesenter N (2020) Klimanormaler. https://klimaservicesenter.no/ faces/desktop/article.xhtml?uri=klimaservicesenteret/ Klimanormaler\&chapterld $=6214$.

37. Schmelz RM. Collado R. A guide to European terrestrial and freshwater species of Enchytraeidae (Oligochaeta). Soil Organisms. 2010;82:1-176

38. Turner GF. Parallel speciation, despeciation and respeciation: implications for species definition. Fish Fish. 2002;3(3):225-9 https://doi.org/10.1046/j.14672979.2002.00085.x

39. Achurra A, Erséus C. DNA barcoding and species delimitation: the Stylodrilus heringianus case (Annelida : Clitellata : Lumbriculidae). Invertebr Syst. 2013; 27(1):118-28 https://doi.org/10.1071/Is12049.

40. Martinsson S, Achurra A, Svensson M, Erséus C. Integrative taxonomy of the freshwater worm Rhyacodrilus falciformis s.l. (Clitellata: Naididae), with the description of a new species. Zool Scr. 2013;42(6):612-22 https://doi.org/10. $1111 /$ zsc.12032.

41. Martinsson S, Erseus C. Cryptic speciation and limited hybridization within Lumbricus earthworms (Clitellata: Lumbricidae). Mol Phylogenet Evol. 2017; 106:18-27 https://doi.org/10.1016/j.ympev.2016.09.011.

42. Giska I, Sechi P, Babik W. Deeply divergent sympatric mitochondrial lineages of the earthworm Lumbricus rubellus are not reproductively isolated. BMC Evol Biol. 2015;15:217 https://doi.org/10.1186/s12862-015-0488-9.

43. Martinsson S, Erséus C. Cryptic diversity in supposedly species-poor genera of Enchytraeidae (Annelida: Clitellata). Zool J Linnean Soc. 2018;183(4):74962 https://doi.org/10.1093/Zoolinnean/zlx084.

44. Martin P, Martinsson S, Wuillot J, Erséus C. Integrative species delimitation and phylogeny of the branchiate worm Branchiodrilus (Clitellata, Naididae). Zool Scr. 2018;47(6):727-42 https://doi.org/10.1111//zsc.12316.

45. Siddall ME, Trontelj P, Utevsky SY, Nkamany M, Macdonald KS. diverse molecular data demonstrate that commercially available medicinal leeches are not Hirudo medicinalis. Proc R Soc Biol Sci Ser B. 2007;274(1617):1481-7 https://doi.org/10.1098/rspb.2007.0248.

46. Papadopoulou A, Bergsten J, Fujisawa T, Monaghan MT, Barraclough TG, Vogler AP. Speciation and DNA barcodes: testing the effects of dispersal on the formation of discrete sequence clusters. Philos Trans R Soc B Biol Sci. 2008;363(1506):2987-96 https://doi.org/10.1098/rstb.2008.0066.

47. Sjögren M, Augustsson A, Rundgren S. Dispersal and fragmentation of the enchytraeid Cognettia sphagnetorum in metal polluted soil. Pedobiologia. 1995:39(3):207-18

48. Eijsackers $\mathrm{H}$. Earthworms as colonizers of natural and cultivated soil environments. Appl Soil Ecol. 2011;50:1-13 https://doi.org/10.1016/j.apsoil. 2011.07.008

49. Lundqvist J. Late Weichselian glaciation and deglaciation in Scandinavia. Quat Sci Rev. 1986;5:269-92 https://doi.org/10.1016/s0277-3791(86)80023-3.

50. Hebert PD, Stoeckle MY, Zemlak TS, Francis CM. Identification of birds through DNA barcodes. PLoS Biol. 2004;2(10):e312 https://doi.org/10.1371/ journal.pbio.0020312.

51. Smith MA, Fisher BL, Hebert PD. DNA barcoding for effective biodiversity assessment of a hyperdiverse arthropod group: the ants of Madagascar. Philos Trans R Soc Lond Ser B Biol Sci. 2005;360(1462):1825-34 https://doi. org/10.1098/rstb.2005.1714

52. Ratnasingham S, Hebert PD. A DNA-based registry for all animal species: the barcode index number (BIN) system. PLoS One. 2013;8(7):e66213 https://doi. org/10.1371/journal.pone.0066213.

53. Dupuis JR, Roe AD, Sperling FA. Multi-locus species delimitation in closely related animals and fungi: one marker is not enough. Mol Ecol. 2012;21(18): 4422-36 https://doi.org/10.1111/j.1365-294X.2012.05642.x.

54. Schmelz RM, Klinth MJ, Chalkia C, Anastasiadou P, Vavoulidou E. Enchytraeus demutatus sp. nov. (Enchytraeidae, Oligochaeta) has characters hitherto 
unrecorded in the genus. Soil Organisms. 2019;91(3):87-96 https://doi.org/ 10.25674/so91iss3pp87u.

55. Katoh K, Misawa K, Kuma K, Miyata TMAFFT. a novel method for rapid multiple sequence alignment based on fast Fourier trasform. Nucleic Acids Res. 2002;30(14):3059-66.

56. Stephens M, Donnelly P. A comparison of bayesian methods for haplotype reconstruction from population genotype data. Am J Hum Genet. 2003; 73(5):1162-9 https://doi.org/10.1086/379378.

57. Stephens M, Smith NJ, Donnelly P. A new statistical method for haplotype reconstruction from population data. Am J Hum Genet. 2001;68(4):978-89 https://doi.org/10.1086/319501.

58. Librado P, Rozas J. DnaSP v5: a software for comprehensive analysis of DNA polymorphism data. Bioinformatics. 2009;25(11):1451-2 https://doi.org/10. 1093/bioinformatics/btp187.

59. Flot J-F, Tillier A, Samadi S, Tillier S. Phase determination from direct sequencing of length-variable DNA regions. Mol Ecol Notes. 2006;6(3):62730 https://doi.org/10.1111/j.1471-8286.2006.01355.x.

60. Flot J-F. CHAMPURU 1.0: a computer software for unraveling mixtures of two DNA sequences of unequal lengtfs. Mol Ecol Notes. 2007;7:974-7 https://doi.org/10.1111/j.1471-8286.2007.01857.x.

61. Kumar S, Stecher G, Li M, Knyaz C, Tamura K. MEGA X: molecular evolutionary genetics analysis across computing platforms. Mol Biol Evol. 2018;35(6):1547-9 https://doi.org/10.1093/molbev/msy096.

62. Puillandre N, Lambert A, Brouillet S, Achaz G. ABGD, automatic barcode gap discovery for primary species delimitation. Mol Ecol. 2012;21(8):1864-77 https://doi.org/10.1111/j.1365-294X.2011.05239.x.

63. Leigh JW, Bryant D. POPART: full-feature software for haplotype network construction. Methods Ecol Evol. 2015;6(9):1110-6 https://doi.org/10.1111/ 2041-210X.12410.

64. Bandelt HJ, Forster P, Rohl A. Median-joining networks for inferring intraspecific phylogenies. Mol Biol Evol. 1999;16(1):37-48 https://doi.org/10 1093/oxfordjournals.molbev.a026036.

65. Guindon S, Dufayard JF, Lefort V, Anisimova M, Hordijk W, Gascuel O. New algorithms and methods to estimate maximum-likelihood phylogenies: assessing the performance of PhyML 3.0. Syst Biol. 2010;59(3):307-2 https://doi.org/10.1093/sysbio/syq010.

66. Lefort V, Longueville J-E, Gascuel O. SMS: smart model selection in PhyML. Mol Biol Evol. 2017;34(9):2422-4 https://doi.org/10.1093/molbev/msx149.

67. Anisimova M, Gascuel O. Approximate likelihood-ratio test for branches: a fast, accurate, and powerful alternative. Syst Biol. 2006;55(4):539-52 https:// doi.org/10.1080/10635150600755453.

68. Rambaut A. FigTree; 2014. p. v1.4.2.

69. Spöri Y, Flot J-F. HaplowebMaker and CoMa: two web tools to delimit species using haplowebs and conspecificity matrices. Methods Ecol Evol. 2020; https://doi.org/10.1111/2041-210x.13454

70. Yang Z, Rannala B. Unguided species delimitation using DNA sequence data from multiple loci. Mol Biol Evol. 2014;31(12):3125-35 https://doi.org/ 10.1093/molbev/msu279.

71. Rannala B, Yang Z. Improved reversible jump algorithms for Bayesian species delimitation. Genetics. 2013;194(1):245-53 https://doi.org/10.1534/ genetics.112.149039.

\section{Publisher's Note}

Springer Nature remains neutral with regard to jurisdictional claims in published maps and institutional affiliations.

Ready to submit your research? Choose BMC and benefit from:

- fast, convenient online submission

- thorough peer review by experienced researchers in your field

- rapid publication on acceptance

- support for research data, including large and complex data types

- gold Open Access which fosters wider collaboration and increased citations

- maximum visibility for your research: over $100 \mathrm{M}$ website views per year

At BMC, research is always in progress.

Learn more biomedcentral.com/submissions 